\title{
Response to the letter to the editor: needle aspiration as an alternative treatment for glioependymal cysts
}

\author{
Luis A. Robles ${ }^{1}$ \\ Received: 7 August 2018 / Accepted: 13 August 2018 / Published online: 21 August 2018 \\ (C) Springer-Verlag GmbH Austria, part of Springer Nature 2018
}

We thank the authors for their interest in our article [4] and for submitting their comments and suggestions related to the treatment of glioependymal cysts. The authors of the letter suggest that stereotactic drainage of glioependymal cysts can be considered as a first-line option in the treatment of these lesions.

We should clarify first that our review included only cases with histopathological confirmation of glioependymal cyst, and cases without histological analysis were eliminated from the study. As consequence, we could have excluded cases treated in different ways if histological analysis was not performed. In our study, we did not find cases treated in the way described by Apra et al., but this does not mean that cases treated in this way do not exist.

Due to the rarity of these lesions, treatment of glioependymal cysts is not standardized which is corroborated by the multiple surgical strategies that exist in the management of these cysts. Even there are previous publications reporting the use of stereotactic aspiration as a single treatment of deep-seated benign cysts with characteristics of glioependymal cysts [1-3]. The results of these studies show a high cyst recurrence after stereotactic drainage, which also happened in the second case presented by Apra et al.

This article is part of the Topical Collection on Tumor - Other

Luis A. Robles

larob@prodigy.net.mx

1 Section of Neurosurgery, Hospiten, Av. Francisco Medina Ascencio 3970, Puerto Vallarta, Jalisco, Mexico
In their first case, a cyst located in the cerebellar peduncle was treated with stereotactic aspiration showing long-lasting clinical improvement in the patient; in addition, the cyst has not shown recurrence on imaging after 4 years. Although histopathological study was not performed in this case, the images are very suggestive of an ependymal or glioependymal cyst.

Due to the aforementioned, we believe it is very risky to consider stereotactic aspiration as a first-line strategy in the management of glioependymal cysts based only on the results of a single case.

We do not deny that stereotactic aspiration can be useful as initial treatment, especially for the management of cysts located in deep and functional brain areas; however, we consider a more definitive option preferable, such as the fenestration of the cyst into cerebrospinal fluid spaces.

We greatly appreciate Apra et al.'s observations regarding the management of glioependymal cysts.

\section{References}

1. Colnat-Coulbois S, Marchal JC (2005) Thalamic ependymal cyst presenting with tremor. Childs Nerv Syst 21(10):933-935

2. Heran NS, Berk C, Constantoyannis C, Honey CR (2003) Neuroepithelial cysts presenting with movement disorders: two cases. Can J Neurol Sci 30(4):393-396

3. Rajshekhar V (1994) Benign thalamic cyst presenting with contralateral postural tremor. J Neurol Neurosurg Psychiatry 57(9):11391140

4. Robles LA, Paez JM, Ayala D, Boleaga-Duran B (2018) Intracranial glioependymal (neuroglial) cysts: a systematic review. Acta Neurochir 160(7):1439-1449 